\title{
A Quantitative and Qualitative Analysis of Electronic Prescribing Incidents Reported by Community Pharmacists
}

\author{
Ana L. Hincapie ${ }^{1}$ Ahmad Alamer ${ }^{2}$ Julie Sears ${ }^{1}$ Terri L. Warholak ${ }^{2}$ Semin Goins ${ }^{1}$ \\ Sara Danielle Weinstein ${ }^{2}$ \\ ${ }^{1}$ James L. Winkle College of Pharmacy, University of Cincinnati, \\ Cincinnati, Ohio, United States \\ 2 The University of Arizona College of Pharmacy, Tucson, Arizona, \\ United States \\ Address for correspondence Ana L. Hincapie, MS, PhD, Division of \\ Pharmacy Practice and Administrative Sciences, James L. Winkle \\ College of Pharmacy, 3225 Eden Avenue 369, Cincinnati, OH 45267. \\ United States (e-mail: hincapaa@ucmail.uc.edu).
}

Appl Clin Inform 2019;10:387-394.

\section{Abstract}

Keywords

- electronic prescribing

- safety

- community pharmacies

- quality

- error reporting
Background Electronic prescribing (e-prescribing) technology was introduced as an alternative to handwritten prescriptions allowing health care professionals to send prescriptions directly to pharmacies. While the technology has many advantages, such as improving pharmacy workflow and reducing medication errors, some limitations have been realized.

Objective The objective of this study was to examine the frequency, type, and contributing factors of e-prescribing quality-related incidents reported to two national error-reporting databases in the United States.

Methods This was a retrospective analysis of voluntarily reports of e-prescribing quality-related incidents. A quantitative and qualitative analysis was conducted of incidents reported between 2011 and 2015 to the Pharmacy Quality Commitment (PQC) and the Pharmacy Provider e-prescribing Experience Reporting Portal (PEER) databases. For the qualitative analysis, events were combined from the PQC and PEER portal and a $10 \%$ random sample of events were analyzed.

Results A total of 589 events were reported to the PEER Portal. Of these, problems with patient directions were the most frequent incident type $(n=210)$ of which $10 \%(n=21)$ reached the patient. Quantity selection $(n=158)$ and drug selection $(n=96)$ were the next most frequently reported events, $20 \%$ of which reached the patient. The PQC system received 550 reports. The most frequent event type reported to this system was incorrect directions $(23.3 \%, n=128)$ followed by incorrect prescriber (17\%), incorrect drug (15\%), and incorrect strength (12\%). The most common theme in the qualitative analysis was a perceived increased likelihood of patient receiving incorrect drug therapy due to eprescribing. Another theme identified included confusion and frustration of pharmacy personnel as result of e-prescription quality-related events.

Conclusion The use of qualitative and quantitative incident data revealed that patient directions and quantity selection were the most common quality issues with e-prescribing. In turn, this may increase the likelihood of patients receiving incorrect drug therapy. received

November 18, 2018 accepted after revision April 23, 2019 (c) 2019 Georg Thieme Verlag KG Stuttgart · New York
DOI https://doi.org/

$10.1055 / \mathrm{s}-0039-1691840$ ISSN 1869-0327. 


\section{Background and Significance}

Electronic prescribing, often referred to as e-prescribing, allows for prescriber or other authorized health care professionals to send an electronic prescription directly to a pharmacy. Many benefits have been attributed to e-prescribing such as reduction in medication errors, ${ }^{1}$ streamlined refill processes, ${ }^{2}$ better formulary management, and improved efficiency for prescribers and pharmacists. ${ }^{3,4}$ E-prescribing is generally well received, mainly because of the reduction of errors that were caused by written prescriptions. E-prescribing has enabled direct communication between physicians' offices and pharmacies through technology; thereby, reducing handwriting interpretation errors significantly. ${ }^{5}$

Although e-prescribing has been beneficial in many ways, some limitations have been realized. ${ }^{2,5-11}$ For example, technology itself has introduced new types of errors (i.e., e-prescribing errors) such as incorrect entry of dosing directions, drug quantity, and patient information, which poses a significant barrier to wider acceptance of e-prescribing systems. ${ }^{11}$ With over 1.74 billion prescriptions submitted electronically in the United States in 2017, the problems arising as result of e-prescribing need to be identified and addressed to keep patients safe. ${ }^{12}$

Although some studies have been conducted to examine the e-prescribing strengths, weaknesses, and types of e-prescribing errors in community pharmacy settings, most studies focus on either quantifying error rates or exploring perceived contributed factors in a limited geographical sample of community pharmacies. ${ }^{1,7,8,10}$ Research of quality issues purportedly caused by e-prescribing in community settings that combine quantitative and qualitative data are still limited. By combining quantitative and qualitative data from two national U.S. incident reporting systems widely used in community pharmacies, we seek to provide a better understanding the context in which e-prescribing incidents occur.

\section{Objectives}

The objectives of this study were to examine quantitatively and qualitatively the frequency type and contributing factors of e-prescribing quality-related problems reported to two national incident-reporting databases.

\section{Methods}

\section{Study Design}

This was a retrospective analysis of voluntarily reports of eprescribing quality-related incidents. The e-prescribing reports for this study were received from two Web-based confidential error-reporting systems developed and offered by the Alliance for Patient Medication Safety (APMS). The reporting systems are the Pharmacy Quality Commitment (PQC) program and the Pharmacy and Provider e-prescribing Experience Reporting Portal (PEER) Portal. These databases were selected due to their data availability on e-prescribing incidents. These two reporting systems are available to U.S. community pharmacies as part of a continuous quality improvement program created to assist pharmacy personnel in documenting, monitoring, and analyzing quality-related events. ${ }^{13,14}$

PQC is a two-part system that enables a pharmacy to identify, document, and analyze workflow. It enables pharmacists to document medication incidents (i.e., near misses, unsafe conditions, and errors that reached the patient) on a standardized electronic form. The report form collects information regarding all steps in the medication dispensing process-where the incident was identified and corrected, the incident type, if e-prescribing was involved, and whether it reached the patient. In addition to collecting data, PQC provides dashboards, tools, recommendations, and resources that allow pharmacists to develop a plan for quality improvement to enhance quality of care. PQC was not designed to specifically collect e-prescribing incidents. Thus, with the intent of expanding the ability to report e-prescribingrelated events, APMS developed the PEER Portal giving pharmacists and other health care providers the ability to report e-prescribing incidents and identify challenges experienced with e-prescribing. The PEER Portal uses an enhanced, Web-based questionnaire that enables pharmacists and other health care providers to easily enter information about e-prescribing challenges and experiences, and at the same time, provide their critical feedback and expertise for improving the e-prescribing process. ${ }^{3}$ APMS implements and maintains both systems under the Patient Safety and Quality Improvement Act of 2005 . $^{15}$

\section{Sample and Data Collection}

This study used a convenience sample of all deidentified eprescribing incidents voluntarily reported by pharmacy personnel to PQC and the PEER Portal between January 2010 and January 2015. As such, data collection occurred electronically through the two systems. The following data elements were obtained from the PQC and PEER Portal data set: (1) date incident was reported; (2) type of prescription (new vs. refill); (3) where the incident was discovered (e.g., pharmacist final check, partner check, patient discovery, counseling, entry, filling, or delivered to patient); (4) incident type (i.e., incorrect drug, strength, directions, quantity, patient); (5) event severity (i.e., near miss and unsafe condition and levels that range from 0 to 6 where 0 indicates that the event reached patient but caused no harm or did not leave the pharmacy [i.e., found in counseling], and 6 indicates patient death); and (6) drugs involved (i.e., medication prescribed, medication dispensed, medication strength).

Additionally, deidentified descriptive incident data (i.e., open-ended data) were extracted to further understanding reasons for e-prescribing incidents.

The PQC data file was cleaned (by deleting duplicates, tests, and dummy reports) and filtered by using a Boolean algorithm to identify reports containing any relationship to e-prescribing in the open text field. This was a text-based rule that allows text categorization. ${ }^{16}$ The programming language identified case-insensitive keywords in the description field that may have indicated an e-prescribing incident (see - supplementary Material [available in the online version] for keywords). The sample extracted using 
this step was subsequently filtered using two discrete data fields in the database: (1) prescribing type (e-prescribing only category), and (2) incident contributing factor "Equipment" category. After this process, hits were termed "eprescribing incidents."

\section{Data Analysis}

\section{Quantitative Analysis}

Descriptive statistics were calculated for all variables of interest for each data source (i.e., PQC and the PEER Portal). Variables summarized for the combined sample included: event type (i.e., incorrect drug, strength, directions, quantity, or patient) and if the incident reached the patient.

\section{Qualitative Analysis}

A $10 \%$ random sample of comments received in the open text fields in each data set was examined. Using Odukoya et al's conceptual framework, ${ }^{8}$ two independent investigators (J.S. and A.A.) codified potential contributing factors for incidents by analyzing the description of each original incident report. This framework was selected because it is the first to identify and organize key factors of e-prescribing errors contributing factors and consequences using a qua- litative approach. Additional categories were created when new themes emerged for contributing factors outside the conceptual framework used. The frequency with which codes and themes were mentioned was tabulated. Disagreements on coding were adjudicated by a third independent reviewer. A third reviewer served as arbitrator when coding discrepancies were found. Qualitative data were managed using Microsoft Excel.

\section{Results}

\section{PEER Portal}

The PEER Portal data file contained 589 incident reports. Between 2010 and 2015, 47.8\% were categorized as near misses, followed by $43 \%$ of the events tagged as unsafe conditions. During this period, 9.2\% $(n=54)$ of the total incident reports reached the patient.

As shown in - Table 1, SIG/Directions problems were the most frequent type of incidents $(n=210)$ of which $10 \%$ $(n=21)$ reached the patients. Quantity selection ( $n=158)$ and drug selection $(n=96)$ were the next most frequently reported errors, $20 \%$ of which reached the patients. Of the total incident types reported $(n=956)$, $7.9 \%$ reached the patients.

Table 1 Frequency and percentages of e-prescribing-related problems in PEER reports ${ }^{\mathrm{a}}$

\begin{tabular}{|c|c|c|c|c|}
\hline e-Prescribing problem category & $\begin{array}{l}\text { Event reached } \\
\text { patient, } n(\%)\end{array}$ & $\begin{array}{l}\text { Near miss, } \\
n(\%)\end{array}$ & $\begin{array}{l}\text { Unsafe condition, } \\
n(\%)\end{array}$ & Total, $n(\%)^{c}$ \\
\hline SIG/directions & $21(10.0)$ & $97(46.2)$ & $92(43.8)^{b}$ & 210 (21.9) \\
\hline Quantity selection & $12(7.6)$ & $80(50.6)$ & $66(41.8)$ & $158(16.5)$ \\
\hline Drug selection & $12(12.5)$ & $52(54.2)$ & $32(33.3)$ & $96(10.0)$ \\
\hline e-Prescription contains conflicting information & $6(6.3)$ & $37(38.5)$ & $53(55.2)$ & $96(10.0)$ \\
\hline Dose selection & $8(8.8)$ & $58(65.2)$ & $23(25.8)$ & $89(9.3)$ \\
\hline Dosage form selection & $3(5.4)$ & $31(56.4$ & $21(38.2)$ & $55(5.7)$ \\
\hline e-Prescription data fields are used inappropriately & $4(9.5)$ & $11(26.2)$ & $27(64.3)$ & $42(4.3)$ \\
\hline e-Prescription missing essential information & 0 & $12(31.6)$ & $26(68.4)$ & 38 (3.9) \\
\hline Incorrect patient & $2(8.0)$ & $18(72.0)$ & $5(20.0)$ & $25(2.6)$ \\
\hline Route selection & 0 & $11(50.0)$ & $11(50.0)$ & $22(2.6)$ \\
\hline $\begin{array}{l}\text { Legibility/font/unsafe nomenclature } \\
\text { or other system design feature }\end{array}$ & $1(5.3)$ & $4(21.1)$ & $14(73.7)$ & 19 (1.9) \\
\hline $\begin{array}{l}\text { Data transmission error that affects the } \\
\text { quality or safety of patient care }\end{array}$ & 0 & $6(40.0)$ & $9(60.0)$ & $15(1.5)$ \\
\hline Controlled substance $^{d}$ & 0 & $4(36.4)$ & $7(63.6)$ & $11(1.1)$ \\
\hline Date selection & $1(16.7)$ & $4(66.7)$ & $1(16.7)$ & $6(0.6)$ \\
\hline $\begin{array}{l}\text { Data fields too small to record } \\
\text { all information input by prescriber }\end{array}$ & 0 & 0 & $6(100)$ & $6(0.6)$ \\
\hline Other & $6(8.8)$ & $14(20.6)$ & $48(70.6)$ & $68(7.1)$ \\
\hline Total & $76(7.9)$ & 439 (45.9) & $441(46.1)$ & 956 \\
\hline
\end{tabular}

aReporters had the option to select more than one category per report.

${ }^{\mathrm{b}}$ Row percentage.

'Column percentage; PEER (Pharmacy and Provider e-prescribing Experience Reporting), SIG (“let it be labeled,” i.e., Directions).

dThis category refers to the reception of an e-prescription for controlled substances where either the provider software was not compliant of Drug Enforcement Administration (DEA) regulations, or the state legislation at the time of reporting did not allow pharmacists to fill e-prescriptions of controlled substances. 
Table 2 Types of QREs reported to PQC from 2011 to 2015

\begin{tabular}{|c|c|c|c|c|c|c|}
\hline \multirow[t]{2}{*}{ QRE type } & \multicolumn{6}{|c|}{ Frequency $(\%)$ of QREs/year $(N=550)$} \\
\hline & 2011 & 2012 & 2013 & 2014 & 2015 & Total $(\%)^{a}$ \\
\hline Incorrect directions & $2(1.6)$ & $39(30.5)$ & $43(33.6)$ & $32(25)$ & $12(9.4)$ & $128(23.3)$ \\
\hline Incorrect prescriber & $1(1.1)$ & $16(17.2)$ & $14(15.1)$ & $36(38.7)$ & $26(28.0)$ & $93(17)$ \\
\hline Incorrect drug & $6(7.4)$ & $17(21.0)$ & $28(34.6)$ & $16(19.8)$ & $14(17.3)$ & $81(14.7)$ \\
\hline Incorrect strength & $2(6.1)$ & $17(26.6)$ & $16(25)$ & $15(23.4)$ & $14(21.9)$ & $64(11.6)$ \\
\hline Incorrect quantity & $2(6.1)$ & $8(24.2)$ & $13(39.4)$ & $8(24.2)$ & $2(6.1)$ & $33(6)$ \\
\hline Order mix-up & 0 & $1(4.8)$ & $6(28.6)$ & $8(38.1)$ & $6(28.6)$ & $21(3.8)$ \\
\hline Refill incorrect & 0 & $2(10.5)$ & $6(31.6)$ & $3(15.8)$ & $8(42.1)$ & $19(3.5)$ \\
\hline Incorrect delivery & $1(11.1)$ & $1(11.1)$ & $2(22.2)$ & $2(22.2)$ & $3(33.3)$ & $9(1.6)$ \\
\hline Incorrect generic substitution & 0 & $3(60.0)$ & $1(20.0)$ & 0 & $1(20.0)$ & $5(0.9)$ \\
\hline Confidentiality & 0 & $1(50.0)$ & $1(50.0)$ & 0 & 0 & $2(0.4)$ \\
\hline Other & $7(7.4)$ & $23(24.2)$ & $29(30.5)$ & $22(23.2)$ & $14(14.7)$ & $95(17.3)$ \\
\hline Total & $21(3.8)$ & $128(23.3)$ & $159(28.9)$ & $142(25.8)$ & $100(18.2)$ & 550 \\
\hline
\end{tabular}

Abbreviations: PQC, Pharmacy Quality Commitment; QRE, quality-related event.

${ }^{a}$ Column percentage.

\section{PQC Data}

The PQC data file yielded a total of 550 incidents after the data cleaning. Similar to PEER data, the most frequent e-prescribing quality-related event type reported to the PQC portal was incorrect directions $23.3 \%(n=128)$ followed by incorrect prescriber (17\%), incorrect drug (15\%), and incorrect strength (12\%) (see -Table 2). These four event types accounted for over two-thirds (67\%) of all events, and were the highest among total number of quality-related events reported in each year. Incident-related to incorrect quantity, order mix-up, refill incorrect, and incorrect delivery reported were below $10 \%$.

Across all years, over one-third of e-prescribing events (37.6\%) reported to the PQC portal were discovered at final pharmacist check (see - Fig. 1). The next most frequent detection points were "order entry" (18.4\%) and patient detection (10\%).

-Table 3 shows the contributing factors reported to the PQC system for years 2011 to 2015. These categories are predefined in the PQC system and reporters are given the option to select multiple categories if necessary. The highest number of quality events was related to human factors such as slips and calculations (79.9\%). The most frequent number of the contributing factor was communication and language barrier, which comprised $8.8 \%$ of the total contributing factors.

\section{Qualitative Analysis}

A sample of 165 events from the PQC and PEER Portal combined database was created. After the coding process, emerging themes were classified in three overall domains: (1) contributing factors to e-prescribing incidents, (2) potential consequences of e-prescribing incidents for patients, and (3) consequences of e-prescribing incidents for pharmacies and pharmacy personnel (see - Table 4).

Contributing factors to e-prescribing incidents: Incorrect calculations or inadequate entry of information into the eprescriptions were commonly described as a quality issue with the electronic prescriptions. Respondents expressed that this may occur due to prescribers' confusion selecting dose and calculating quantity while using the system. In other cases, the confusion was attributed to the use of auto-

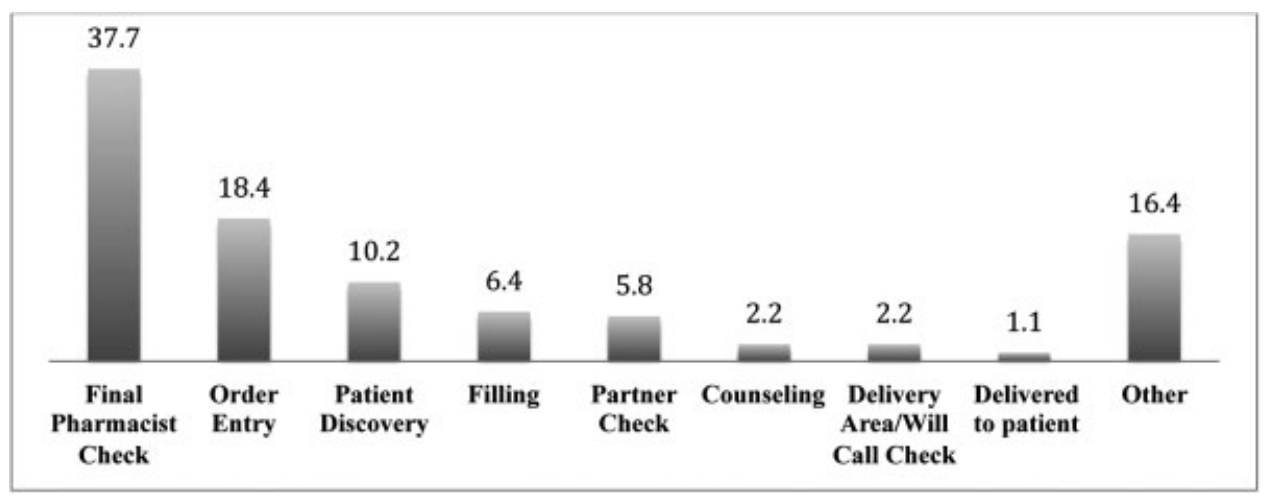

Fig. 1 Percentage of detection points for events reported to the Pharmacy Quality Commitment (PQC) $(N=550)$. 
Table 3 Contributing factors of QREs as reported to PQC system

\begin{tabular}{|l|l|}
\hline Contributing factors & $N(\%)$ \\
\hline $\begin{array}{l}\text { Human factors } \\
\text { (e.g., slips or wrong calculations) }\end{array}$ & $410(79.9)$ \\
\hline Communication/Language barrier & $45(8.8)$ \\
\hline Training/Supervision factor & $26(5.0)$ \\
\hline Pharmacy factors (culture/policies/staffing) & $21(4.1)$ \\
\hline Patient factor & $7(1.3)$ \\
\hline $\begin{array}{l}\text { Weights/Measurement/High-risk } \\
\text { nomenclature }\end{array}$ & $4(0.9)$ \\
\hline
\end{tabular}

Abbreviations: PQC, Pharmacy Quality Commitment; QRE, quality-related event.

filled directions on the electronic system. Drug field autopopulation features were identified in as the root cause for selecting the wrong drug, especially when drugs looked alike on the computer screen. Similarly, reports suggested that auto-population might have facilitated errors such as selecting the incorrect drug salt (e.g., metoprolol succinate vs. metoprolol tartrate), or capsules instead of tablets. These differences may result in filling extended release versus immediate release drugs. Another contributing factor of eprescribing incidents was the mismatch of e-prescription information between prescriber and pharmacy systems. Reports suggested that discrepancies between drug information files of the e-prescribing system and the pharmacy information system might have caused errors such as incorrect drug strengths.

Potential consequences of e-prescribing incidents for patients: Reporters highlighted the potential of increasing patients' risks of receiving the incorrect therapy in the form of incorrect drug or incorrect strength. This was attributed to errors during the electronic selection of medications in the computer screen. The reports also described how incidents with e-prescribing caused a delayed processing of prescriptions. This may cause patients' frustration as their expectations regarding store pick-up times might have changed with the use of e-prescribing.

Potential consequences of e-prescribing incidents for pharmacies and pharmacy personnel: There were three themes commonly mentioned as results of e-prescribing incidents for pharmacies and their personnel. First, incidents may

Table 4 Summary of thematic analysis results

\begin{tabular}{|c|c|c|c|}
\hline Domain & Theme & $N(\%)$ & Representative verbatim quotes \\
\hline \multirow[t]{4}{*}{$\begin{array}{l}\text { Factors contributing } \\
\text { to e-prescription } \\
\text { incidents }\end{array}$} & $\begin{array}{l}\text { Incorrect calculation or } \\
\text { entry of information }\end{array}$ & $\begin{array}{l}61 \\
(24.0)\end{array}$ & $\begin{array}{l}\text { "Prescription received [...] } 25 \mathrm{mg} \text { tablet. Quantity prescribed \#90. } \\
\text { Sig: "Take } 1 \text { tablet ( } 25 \mathrm{mg} \text { total) by mouth } 2 \text { times a day." Patient } \\
\text { misunderstood this to mean he was to take } 1 / 2 \text { tablet twice a day to } \\
\text { give him a total daily dose of } 25 \mathrm{mg} \text { per day. Dosage should have } \\
\text { been } 1 \text { whole tablet ( } 25 \mathrm{mg} \text { ) twice a day for a total daily dose of } \\
50 \mathrm{mg} \text { per day. Health system recently changed their program- } \\
\text { ming to include the notation of total dose. I think this will be } \\
\text { confusing for the patients - and this is just the first example of a } \\
\text { medication error caused by this programming change." } \\
\text { "Doctor sent an e-Rx and put one set of directions in the sig and } \\
\text { another set of directions in prescriber notes." }\end{array}$ \\
\hline & $\begin{array}{l}\text { Auto-population of } \\
\text { e-prescription information }\end{array}$ & $\begin{array}{l}14 \\
(5.5)\end{array}$ & $\begin{array}{l}\text { "Processing refill for patient's [...] ER } 10 \mathrm{mEq} \text { capsules. Physi- } \\
\text { cian e-prescribed [...] CR } 10 \text { mEq tablets, with the electronic sig } \\
\text { of: Take two capsules twice daily. We have seen this many } \\
\text { times - with orders getting mixed up on [...] capsules vs. } \\
\text { tablets. [...]- these always come up capsules since this is easier } \\
\text { to find in their ordering systems!" }\end{array}$ \\
\hline & $\begin{array}{l}\text { Mismatch of e-prescription } \\
\text { information between } \\
\text { prescriber and } \\
\text { pharmacy systems }\end{array}$ & $\begin{array}{l}18 \\
(7.1)\end{array}$ & $\begin{array}{l}\text { "E-prescription came, but it did not match directly with pharmacy } \\
\text { system drug file and pharmacist had to manually choose the } \\
\text { strength. The error was not discovered by the pharmacist who } \\
\text { entered the drug, nor by the pharmacist who checked the } \\
\text { prescription. The patient had a proxy pick up the prescription and } \\
\text { the patient discovered the error when it came home. If the } \\
\text { pharmacy system matched better to the e-Prescribe Rx product } \\
\text { and if the system made it more difficult to choose a non- } \\
\text { equivalent product, then this error would not occur so easily." }\end{array}$ \\
\hline & Error due to interface failure & $\begin{array}{l}26 \\
(10.2)\end{array}$ & $\begin{array}{l}\text { "Pharmacy received } 2 \text { E-Rx prescriptions for the same patient } \\
\text { on same day by } 2 \text { different providers. [...] was time stamped at } \\
\text { 12:37 by provider A. [...] was time stamped at 12:38 by } \\
\text { provider B. Provider B was not onsite at this ambulatory } \\
\text { outpatient clinic working on that day. Due to high risk } \\
\text { medication, different providers, and timing the pharmacist } \\
\text { looked in the EMR ([...]) for more information. There was NO } \\
\text { record of [...] prescribed that day in current or historical } \\
\text { records. The apparent computer glitch was reported to IT." }\end{array}$ \\
\hline
\end{tabular}

(Continued) 
Table 4 (Continued)

\begin{tabular}{|c|c|c|c|}
\hline Domain & Theme & $N(\%)$ & Representative verbatim quotes \\
\hline \multirow[t]{2}{*}{$\begin{array}{l}\text { Potential consequences } \\
\text { of incidents for patients }\end{array}$} & $\begin{array}{l}\text { Increased likelihood of } \\
\text { patient receiving incorrect } \\
\text { drug therapy }\end{array}$ & $\begin{array}{l}79 \\
(31.1)\end{array}$ & $\begin{array}{l}\text { "This prescription was sent over Electronically, with the wrong } \\
\text { drug. We filled the prescription with [...] 100mg it should have } \\
\text { been [...] 10mg. The doctors office just clicked on the wrong drug } \\
\text { and sent it over electronically. The patient called the store back to } \\
\text { let us know there was a mistake and that she had taken none of } \\
\text { the medicine \& they were bringing it back to get the correct drug." }\end{array}$ \\
\hline & $\begin{array}{l}\text { Patient frustration due } \\
\text { delayed dispensing } \\
\text { caused by } \\
\text { e-prescription errors }\end{array}$ & $\begin{array}{l}4 \\
(1.6)\end{array}$ & $\begin{array}{l}\text { "We received a prescription for [...] 250mg/5ml suspension to } \\
\text { dispense } 100 \mathrm{ml} \text { with sig: Take by mouth } 3 \text { times daily. Take } 3 \\
\text { times daily until gone. How much? If one teaspoon tid then does } \\
\text { he really still just want } 100 \mathrm{ml} \text { or } 10 \text { days which would be } 100 \mathrm{ml} \text { ? } \\
\text { Had to call for dosage and quantity clarification. Of course patient } \\
\text { is upset they have to wait and it's pharmacy's fault because "the } \\
\text { doctor said with this new computer system this would be ready } \\
\text { when we got here." And of course, physician left building so they } \\
\text { have to track him down to clarify sig." }\end{array}$ \\
\hline \multirow[t]{3}{*}{$\begin{array}{l}\text { Potential consequences } \\
\text { of incidents for } \\
\text { pharmacies and } \\
\text { pharmacy personnel }\end{array}$} & $\begin{array}{l}\text { Slows down pharmacy } \\
\text { workflow and results in } \\
\text { additional work }\end{array}$ & $\begin{array}{l}11 \\
(4.3)\end{array}$ & $\begin{array}{l}\text { "Prescriber sent rx for [...] with sig of } 2 \text { puffs eight times daily } \\
\text { resulting a phone call. Do you want } 2 \text { puffs eight times daily } \\
\text { (maxi listed is } 12 \text { puffs in } 24 \text { hours) or do you want } 2 \text { puffs } \\
\text { every } 8 \text { hours? [...] the doctor and nurse are both gone until } \\
\text { the end of the week, a wait time of } 4 \text { days." }\end{array}$ \\
\hline & $\begin{array}{l}\text { Confusion and frustration } \\
\text { for pharmacy personnel }\end{array}$ & $\begin{array}{l}37 \\
(14.6)\end{array}$ & $\begin{array}{l}\text { "We continue to receive rx's from a particular doctor with drug } \\
\text { selection errors, free text drugs, and drugs that the patients } \\
\text { say they are no longer taking or do not want. We have one } \\
\text { patient that we have received \#20 rx's in July and August and } \\
\text { they did not pick up. I am getting tired of receiving rx's that I } \\
\text { receive no financial benefit from in filling the rx. We also are } \\
\text { sent OTC's which we don't fill. Why should I pay for these?" }\end{array}$ \\
\hline & $\begin{array}{l}\text { Increased cost, audit, } \\
\text { and insurance } \\
\text { billing issues for pharmacy }\end{array}$ & $\begin{array}{l}4 \\
(1.6)\end{array}$ & $\begin{array}{l}\text { "Prescriber denies refills citing reason "new rx to follow" and } \\
\text { send in rx for same dose \& directions as in refill request. the } \\
\text { pharmacy pays the extra costs involved for such misuse. also, } \\
\text { the pharmacy pays the extra costs when prescribers send } \\
\text { duplicates \& mistakenly send prescriptions for incorrect } \\
\text { patients who use different pharmacies. prescribers tend to } \\
\text { phone the pharmacy at that point to cancel the prescription } \\
\text { citing unintended pharmacy." } \\
\text { "This issue has to deal with the cost toward each pharmacy for } \\
\text { each e prescription sent. This is an unbelievable and unnecessary } \\
\text { cost pharmacies have to now incorporate into their bottom lines. } \\
\text { This goes along with lower insurance reimbursements. Thanks a } \\
\text { lot for this extra cost that is basically taken out of our pockets." }\end{array}$ \\
\hline
\end{tabular}

cause delays in the pharmacy workflow and potentially create additional work originating from additional checks and extra time taken to reach out prescribers to clarify eprescriptions. Comments suggesting pharmacy personnel frustration and confusing were also identified. Finally, eprescribing incidents may cause additional costs. Pharmacies pay for the extra cost of prescriptions when prescribers send multiple prescriptions to later cancel them via phone citing submission to the wrong pharmacy as cancellation reason.

\section{Discussion}

The benefits attributed to the use of e-prescribing technology are generally well accepted. ${ }^{17}$ However, e-prescribing users are increasingly appreciating that technology may be prone to quality-related events that result in either medication errors or disruptions in the pharmacy workflow. This poses as a key barrier for a wider acceptance of the e- prescribing. This study combined and quantified e-prescribing quality-related events reported to two Web-based incident reporting systems. We found that about one-third of events reported to both systems corresponded to near misses. This indicates that many incidents were corrected by technicians or pharmacists before reaching the patient. Moreover, events that reached the patients were rated as low severity.

The most frequent types of e-prescribing-related problems found in the PEER Portal and PQC data were in patient directions, incorrect drug, incorrect dose, and incorrect quantity. These findings are consistent with results of previous studies. ${ }^{5}$ A recent literature review, which include 73 peer-reviewed articles, found that e-prescribing errors were most commonly related to wrong strength, wrong quantity, dose and drug selection, patient directions, and duplicate e-prescriptions.

Thematic analysis was performed to assess contributing factors and potential consequences of e-prescribing problems. 
Data reports from both the PEER Portal and PQC systems were combined to codify and categorize contributing factors. Findings suggest almost one-third of potential consequences due to e-prescribing issues for patients were a potential increased likelihood of receiving incorrect drug therapy and patients experiencing frustration due to delayed dispensing of drugs. Over half the issues might have been prevented if the following three recommendations were followed: (1) use of standardized drug descriptions; (2) use of valid and appropriate prescription quantities; and (3) maintain an accurate and up-to-date prescriber and pharmacy information in the Surescripts directory. Given that other studies have found discrepancies among free text, National Drug Code, and RxNorm identifiers, ${ }^{18}$ our study supports the adoption of system changes such as including the use of better standards to decrease quality issues with eprescribing and improving safety.

The in-depth analysis of e-prescribing quality-related events of this study suggests that a small number of system level changes have the potential to have a large impact on improving e-prescribing efficiency and safety. These system changes include: limiting or eliminating free text that contradicts information in structured fields; facilitating communication for refills request, change, or hold; using tall man lettering for brand and generic, and for commonly confused drugs; creating a messaging system to avoid e-prescribing resubmissions and duplicates; and using currently available standards that permit the use of "Cancel Prescription Request and Prescription Change Request" messaging in the electronic health record systems. Surescripts and Institute for Safe Medication Practices (ISMP) have issued guidelines for medication order transfer and the electronic display of medications to improve medication safety. ${ }^{19,20}$ Surescripts guidelines provide recommendations regarding how patient information and pharmacy information should be displayed, while the ISMP focuses in the display of medication information. Surescripts and ISMP include additional recommendations such as utilizing the standardized medication (RxNorm) names only and the inclusion of medications suffixes for the generic and brand name within the input field. Following these recommendations may assist providers in selecting the appropriate pharmacy store selection for script submission and ensuring the correct patient and correct therapy. However, it is still unknown the extent to which adoption of these recommendations influences medication safety and workflow in community pharmacy. Future research might shed light on this area.

Many of the abovementioned system level changes can be addressed by a wider adoption of the most updated National Council for Prescription Drug Programs SCRIPT standards. Despite their availability, their implementation remains subpar. ${ }^{18,21}$ As e-prescribing gains wider adoption, ${ }^{22}$ it is imperative to address the quality-related issues revealed in this project. The volume e-scripts, and therefore the likelihood of incidents, may continue increasing. While these system changes occur, appropriate training of prescribers may guarantee the correct use of free text and other fields that are causing confusion and potentially medication errors. A recent review of prescriber's training on e-prescribing use found limited information suggesting prescribers are being taught their potential contribution to e-prescribing system process failures. $^{23}$

The findings in this study should be interpreted in light of some limitations. First, the analysis was based on selfreporting of incidents. Therefore, it is not possible to draw conclusions about event incidence or prevalence. Second, it is possible that some reports might have been excluded from the initial PQC sample due to need to search incidents using open text fields and the limitation of the Boolean algorithm. Third, due to the spontaneous nature of the data capture, reports may not be representative of all potential safety issues related to e-prescribing. Similarly, a proportion of reports classified as "other" were not analyzed in this study which may have left out additional unexplored themes. E-prescribing is a two-way communication system, thus this study does not address issues prescribers may experience with e-prescribing. Finally, we used aggregated data that were collected since 2010. Initially, there might have been limited reporting while the systems were adopted into the pharmacy workflow. Subsequently, some quality issues might have become less frequent or irrelevant as SCRIPT standards have gained wider implementation. Despite these limitations, the approach of combining qualitative and quantitative data in our study allowed for a deeper insight into the quantity and nature of common quality-related events with e-prescribing, highlighting some areas where there is still work to be done to achieve a safe and efficient e-prescribing technology. This study underscores the need for policy changes that spearhead the use of standards for e-prescribing and better training for users of e-prescribing. Most of the quality issues found in this study could be resolved with limited system changes that are currently available.

\section{Conclusion}

In summary, quantitative data analysis of e-prescribing quality-related events found patients' directions and drug quantity selection as the most frequent issues reported in the incident reporting databases analyzed. Qualitative data analysis showed these e-prescribing incidents may increase the likelihood of patients receiving the incorrect drug therapy and have negative consequences for pharmacies and pharmacy personnel. Reporting of e-prescribing incidents highlighted the need for pharmacists to proceed with caution when processing electronic scripts.

\section{Clinical Relevance Statement}

We described research conducted on electronic prescribing incidents detected in community pharmacies and reported to two U.S. databases. Analyses showed issues with information related to patients' directions and quantity selection in the electronic prescriptions received in community pharmacies. Practitioners, their organizations, and community pharmacists should implement system changes to prevent these potential issues reaching patients. 


\section{Multiple Choice Questions}

1. Which of the following databases was used to collect data in this study?

a. Institute for Safe Medication Practices Error Reporting Portal.

b. Pharmacy Quality Commitment Portal.

c. Surescripts Incident Reporting Portal.

d. National Coordinating Council for Medication Error Reporting.

Correct Answer: The correct answer is option b.

2. The most frequent incident type with electronic prescriptions reported by community pharmacists found in this study was:
a. Quantity selection.
b. Drug selection.
c. Patient directions.
d. Incorrect prescriber.

Correct Answer: The correct answer is option c.

\section{Protection of Human and Animal Subjects}

This study was performed in compliance with the World Medical Association Declaration of Helsinki on Ethical Principles for Medical Research Involving Human Subjects. This study was considered nonhuman research by the Institutional Review Board at the University of Cincinnati, 20155596.

\section{Funding}

This project was funded by a grant from the Community Pharmacy Foundation.

\section{Conflict of Interest}

A.L.H., S.G., J.S., and T.L.W., report grants from Community Pharmacy Foundation, during the conduct of the study.

\section{References}

1 Odukoya OK, Chui MA. E-prescribing: a focused review and new approach to addressing safety in pharmacies and primary care. Res Social Adm Pharm 2013;9(06):996-1003

2 Odukoya O, Chui MA. Retail pharmacy staff perceptions of design strengths and weaknesses of electronic prescribing. J Am Med Inform Assoc 2012;19(06):1059-1065

3 Hincapie AL, Warholak T, Altyar A, Snead R, Modisett T. Electronic prescribing problems reported to the Pharmacy and Provider ePrescribing Experience Reporting (PEER) portal. Res Social Adm Pharm 2014;10(04):647-655

4 Reed-Kane D, Kittell K, Adkins J, Flocks S, Nguyen T. E-prescribing errors identified in a compounding pharmacy: a quality-improvement project. Int J Pharm Compd 2014;18(01):83-86
5 Esmaeil Zadeh P, Tremblay MC. A review of the literature and proposed classification on e-prescribing: Functions, assimilation stages, benefits, concerns, and risks. Res Social Adm Pharm 2016; 12(01):1-19

6 Warholak TL, Rupp MT. Analysis of community chain pharmacists' interventions on electronic prescriptions. J Am Pharm Assoc (2003) 2009;49(01):59-64

7 Rupp MT, Warholak TL. Evaluation of e-prescribing in chain community pharmacy: best-practice recommendations. J Am Pharm Assoc (2003) 2008;48(03):364-370

8 Odukoya OK, Stone JA, Chui MA. E-prescribing errors in community pharmacies: exploring consequences and contributing factors. Int J Med Inform 2014;83(06):427-437

9 Redwood S, Rajakumar A, Hodson J, Coleman JJ. Does the implementation of an electronic prescribing system create unintended medication errors? A study of the sociotechnical context through the analysis of reported medication incidents. BMC Med Inform Decis Mak 2011;11(01):29

10 Odukoya OK, Stone JA, Chui MA. Barriers and facilitators to recovering from e-prescribing errors in community pharmacies. J Am Pharm Assoc (2003) 2015;55(01):52-58

11 Gagnon M-P, Nsangou É-R, Payne-Gagnon J, Grenier S, Sicotte C. Barriers and facilitators to implementing electronic prescription: a systematic review of user groups' perceptions. J Am Med Inform Assoc 2014;21(03):535-541

12 Surescripts. National Progress Report on E-prescribing; 2017. Available at: https://surescripts.com/docs/default-source/national-progress-reports/2151_npr_2017_finalB.pdf. Accessed May 10, 2019

13 Scott DM, Friesner DL, Rathke AM, Peterson CD, Anderson HC. Differences in medication errors between central and remote site telepharmacies. J Am Pharm Assoc (2003) 2012;52(05):e97-e104

14 Chinthammit C, Rupp MT, Armstrong EP, Modisett T, Snead RP, Warholak TL. Evaluation of a guided continuous quality improvement program in community pharmacies. J Pharm Policy Pract 2017; 10(01):26

15 Fassett WE. Patient safety and quality improvement act of 2005 . Ann Pharmacother 2006;40(05):917-924

16 Zhao Z, Cox J, Albright R, Jin N, eds. Using Boolean Rule Extraction for Taxonomic Text Categorization for Big Data. SAS Conference2015

17 Porterfield A, Engelbert K, Coustasse A. Electronic prescribing: improving the efficiency and accuracy of prescribing in the ambulatory care setting. Perspect Health Inf Manag 2014;11(Spring):1g

18 Dhavle AA, Ward-Charlerie S, Rupp MT, Kilbourne J, Amin VP, Ruiz J. Evaluating the implementation of RxNorm in ambulatory electronic prescriptions. J Am Med Inform Assoc 2016;23(Suppl 1):e99-e107

19 Surescripts. E-Prescribing Quality Guidelines; 2016. Available at: https://surescripts.com/company-initiatives/quality-program/ quality-resources/. Accessed May 10, 2019

20 ISMP. Guidelines for the Safe Electronic Communication of Medication Information Safe Presentation. Horsham, PA: Institute for Safe Medication Practices; 2015

21 Liu H, Burkhart Q, Bell DS. Evaluation of the NCPDP structured and codified Sig format for e-prescriptions. J Am Med Inform Assoc 2011;18(05):645-651

22 Wormser GP, Erb M, Horowitz HW. Are mandatory electronic prescriptions in the best interest of patients? Am J Med 2016;129 (03):233-234

23 Brown CL, Reygate $\mathrm{K}$, Slee $\mathrm{A}$, et al. A literature review of the training offered to qualified prescribers to use electronic prescribing systems: why is it so important? Int J Pharm Pract 2017;25(03):195-202 